\title{
RANCANG BANGUN ALAT MONITORING DAYA DENGAN HMI BERBASIS ARDUINO UNO SEBAGAI OPC
}

\author{
Resa Pramudita ${ }^{1}$, Neris Peri Ardiansyah ${ }^{2}$ \\ Departemen Pendidikan Teknik Elektro ${ }^{1,2}$ \\ Universitas Pendidikan Indonesia, \\ Jalan Setiabudhi No. 229, Kota Bandung \\ resa.pd@upi.edu,nerisperia@upi.edu
}

\begin{abstract}
Abstrak
Listrik merupakan unsur yang tidak dapat dihilangkan dalam perkembangan teknologi. Setiap rumah memiliki daya maksimal yang dapat bekerja pada waktu yang sama. Jika pemakaian melebihi dari daya listrik, secara otomatis ACB akan memutuskan jalur secara keseluruhan. Pada kesempatan ini dikembangkan alat pengontrol daya menggunakan komputer dengan arduino sebagai OPC. Sensorsensor yang digunakan di antaranya adalah sensor arus ACS712 dan tegangan ZMPT101B sebagai sensor untuk mengetahui daya pada beban. Alat ini bekerja secara otomatis yang dikendalikan dan dimonitor melalui komputer.
\end{abstract}

Kata kunci :

Daya Listrik, ACS712, ZMPT101B, Arduino Uno OPC, Komputer

\begin{abstract}
Electricity is one a thing that always needed in technological development. Every house has a maximum power that operate at the same time. If the use is over the electrical power that the house have, automatically $A C B$ will cut electric line in that house. This project developing a device to control power using a computer with arudino uno as OPC. Sensors that are used are current sensor ACS712, and voltage sensor ZMPT101B as a sensor to determine the power at the load. This device working automatically and controlled by a computer.
\end{abstract}

Keywords :

Electrical Power, ACS712, ZMPT101B, Arduino Uno OPC, Computer.

\section{Pendahuluan}

Listrik merupakan salah satu unsur yang tidak dapat dihilangkan pada perkembangan teknologi dan ilmu pengetahuan saat ini. Banyak perangkat teknologi yang menggunakan listrik sebagai sumber tenaganya.

Setiap rumah memiliki daya maksimal yang dapat bekerja dalam waktu yang sama yang berbeda dari satu yang lainnya yang bergantung dari pilihan daya listrik yang digunakan. Saai ini, ketika banyak perangkat listrik yang digunakan secara bersamaan pemakaian daya listrik akan bertambah. Jika pemakaian melebihi dari daya listrik yang dipilih maka secara otomatis ACB (Automatic Circuit Breaker) akan mematikan jalur secara keseluruhan.

Pada kesempatan ini dikembangkan alat pengontrol daya rumah menggunakan Arduino Uno. Alat ini dapat mengontrol dan memonitor daya beban yang digunakan sehingga hanya beban dengan daya terbesar yang diputus jalurnya tanpa mematikan seluruh beban yang sedang digunakan pada saat tertentu.

\section{KAJIAN LITERATUR}

\section{II.1 Daya Listrik}

Daya adalah banyaknya perubahan energi terhadap waktu dalam besaran tegangan dan arus. Daya listrik dapat dibagi menjadi 3 yaitu daya nyata $(\mathrm{P})$, daya reaktif $(\mathrm{Q})$, dan daya semu $(\mathrm{S})$.

- Daya nyata P merupakan daya sebenarnya yang dibutuhkan oleh beban-beban listrik/peralatan rumah tangga. Satuan daya nyata adalah watt (W).

- Daya reaktif Q adalah daya yang timbul karena adanya pembentukan medan magnet pada beban- 
beban induktif. Satuan dari daya reaktif adalah volt ampere reaktif (VAR).

- Daya semu merupakan resultan antara daya nyata dan daya reaktif. Satuan dari daya semu adalah volt ampere (VA).

Faktor daya (Cos $\varphi)$ merupakan suatu konstanra pengali dengan nilai 0 sampai 1 , yang menunjukkan seberapa besar daya nyata yang diserap oleh beban resistif dari daya semu yang ada pada suatu beban total. (Ardiansyah \& Khayam, 2019c, 2019b, 2019a; Ardiansyah, Khayam, \& Nurdiansyah, 2020; Ardiansyah \& Pramudita, 2020; Zuhal, 1995)

\section{II.2 Sensor Tegangan (ZMPT101B)}

Pengukuran tegangan AC dapat dilakukan dengan cara mengubah sinyal AC menjadi DC agar lebih mudah dibaca oleh mikrokontroler. Sensor tegangan ZMPT101B telah dilengkapi summing- amplifier sehingga dapat digunakan untuk menaikkan tegangan negatif sehingga dapat digunakan untuk pengukuran tegangan dengan menggunakan mikrokontroler.

Sensor ini dapat digunakan pada tegangan pengoperasian sebesar $250 \mathrm{VAC}$ dan mengeluarkan sinyal analog yang dapat dikonversikan menjadi sinyal digital oleh mikrokontroler. Sensor ini memiliki 4 pin diantaranya pin 1 dan pin 2 untuk input utama dan pin 3 dan 4 untuk output. Sensor tegangan ZMPT101B memiliki isolasi tegangan sebesar 4000V dan bekerja optimal pada suhu 40C sampai 70C. (Kadir, 2013)

\section{II.3 Sensor Arus (ACS712)}

Sensor arus ACS712 merupakan jenis sensor yang digunakan untuk mendeteksi arus pada suatu kawat/kabel dalam instalasi listrik. Sensor ini dapat digunakan untuk mengukur arus searah (DC) dan arus bolak-balik (AC) menggunakan prinsip Hall Effect. Sensor yang memiliki prinsip Hall Effect dirancang untuk mendeteksi objek magnetis dengan perubahan posisi. Adanya perubahan medan magnet secara terus menerus menimbulkan adanya pulsa yang kemudian dapat diambil frekuensinya. Sensor ACS712 mengeluarkan tegangan 2,5 volt jika tidak ada arus. (Julien Bayle, 2013)

\section{II.4 Arduino}

Arduino adalah kit elektronik atau papan rangkaian elektronik open source yang di dalamnya terdapat komponen utama yaitu sebuah chip dengan jenis AVR dari perusahaan Atmel.
Arduino dikatakan sebagai sebuah platfrom dari physical computing yang bersifat open source. Pertama-tama perlu dipahami bahwa kata "platform" di sini adalah sebuah pilihan kata yang tepat. Arduino tidak hanya sekedar sebuah alat pengembangan, tetapi kombinasi dari perangkat keras, bahasa pemrograman dan Integrated Development Environment (IDE) yang canggih. IDE adalah sebuah software yang sangat berperan untuk menulis program, meng-compile menjadi kode biner dan meng-upload ke dalam memory mikrokontroler. (Malik Ibnu \& Juwana Unggul, 2009)

\section{Metodologi Penelitian}

Dalam proyek ini dibuat suatu prototipe alat pengontrol dan pemonitor daya melalui interface komputer yang dihubungkan dengan arduino uno sebagai OPC. Diagram blok dari alat yang dirancang ditunjukkan pada Gambar 1.

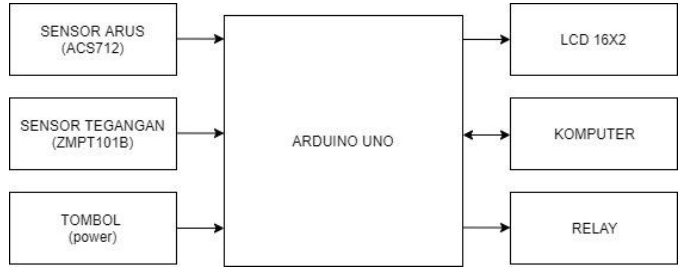

Gambar 1. Diagram Blok Sistem

\section{III.1 Fungsi dan Cara Kerja}

Alat ini di desain dalam bentuk kotak. Alat ini menggunakan 1 buah sensor tegangan ZMPT101B, 3 buah sensor arus ACS712, 3 buah modul relay, 1 buah Arduino Uno, 1 buah modul LCD, dan 1 buah modul I2C LCD.

Alat ini bekerja dengan cara mengecek nilai dari sensor arus dan sensor tegangan yang datanya diolah oleh arduino uno. Ketika daya pada beban melebihi nilai yang sudah ditentukan, secara otomatis relay akan memutus jalur pada beban tersebut tanpa memutus jallur semua beban. Arduino uno difungsikan sebagai OPC yang menghubungkan sensor dengan komputer. Alat ini dikontrol dan dimonitor melalui komputer.

\section{III.2 Perancangan Perangkat Elektronika}

- Rangkaian Regulator

Rangkaian regulator ini menggunakan IC LM338. Sumber tegangan berasal dari adaptor 9 volt. Gambar rangkaian regulator ditunjukkan pada Gambar 2. (Instruments, 2013) 


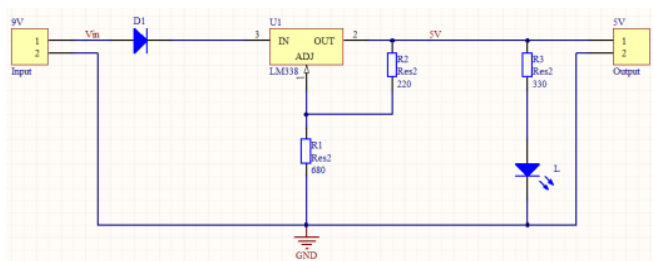

Gambar 2. Rangkain Regulator $+5 \mathrm{Vdc}$

- Rangkaian Elektronika Sistem

Rangkaian secara keseluruhan terdiri dari sensorsensor sebagai masukkan dan relay sebagai keluaran serta Arduino Uno sebagai OPC menghubungkan antara sensor dengan komputer serta kopmuter yang mengolah nilai-nilai dari sensor dan mengontrol serta memonitor nilai sensor dan relay. Gambar 3 menunjukkan rangkain yang sudah dibuat. (Anwar, 2016)

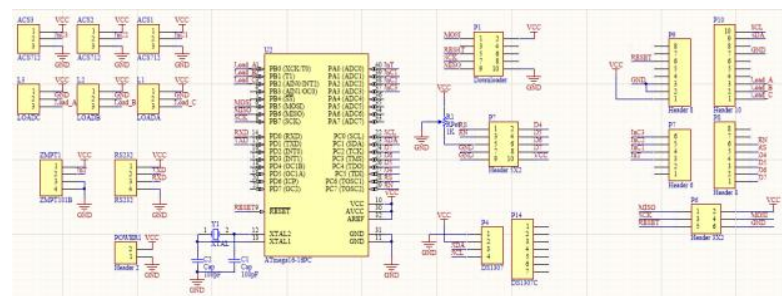

Gambar 3. Rangkaian Elektronika Secara Keseluruhan

\section{Analisis dan Perancangan}

\section{IV.1 Hasil Perancangan Mekanik}

Hasil perancangan mekanik berupa box sebagai tempat penempatan komponen elektronik dengan panjang $23.5 \mathrm{~cm}$, lebar $23.5 \mathrm{~cm}$, dan tinggi $7.5 \mathrm{~cm}$. Bahan yang digunakan adalah plastik, karena selain mudah dibentuk dan ringan juga merupakan isolator yang tidak akan mempengaruhi rangkaian.

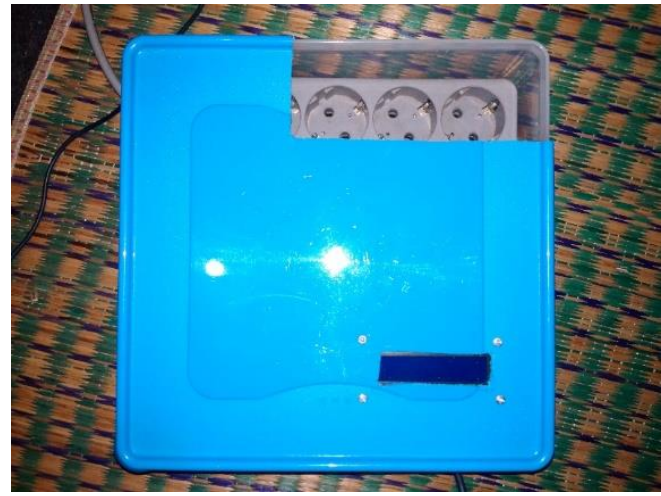

Gambar 4. Hasil Perancangan Mekanik Alat

\section{IV.2 Hasil Perancangan Elektronik}

Hasil dari perancangan elektronik terdapat dua jenis PCB yaitu rangkaian rengkain shield Arduino Uno dan rangkaian regulator.

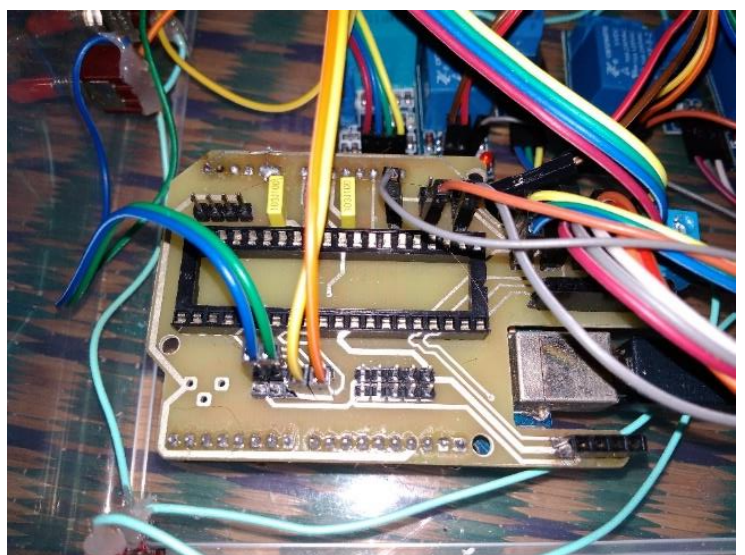

Gambar 5. Hasil Perancangan Rangkaian Shield Arduino Uno

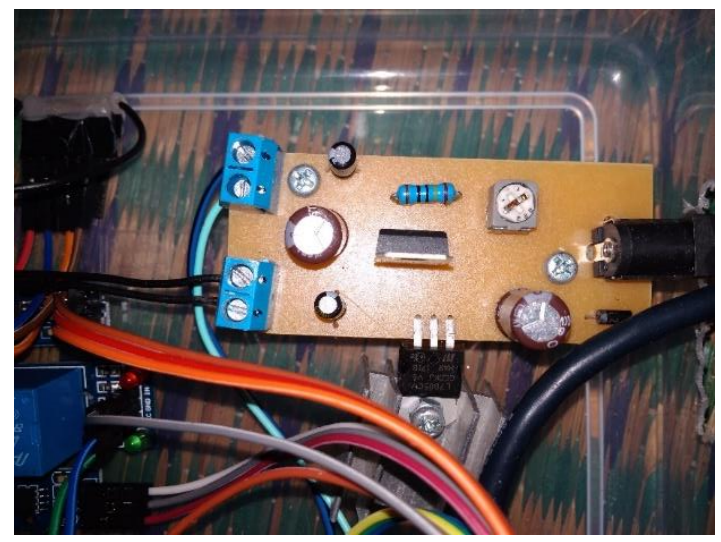

Gambar 6. Hasil Perancangan Rangkaian Regulator

\section{IV.3 Hasil Keseluruhan Perancangan Alat}

Hasil keseluruhan perancangan alat memperlihatkan penggabungan perangkat keras alat yang terdiri dari hasil perancangan elektronik dan mekanik. Gambar IV.4 memperlihatkan posisi penempatan dari rangkaian elektronik alat dengan shield arduino dan regulator diletakkan di bawah alat, sensor-sensor dan relay diletakkan di bagian tengah dan, serta stop kontak dibagian depan alat. 


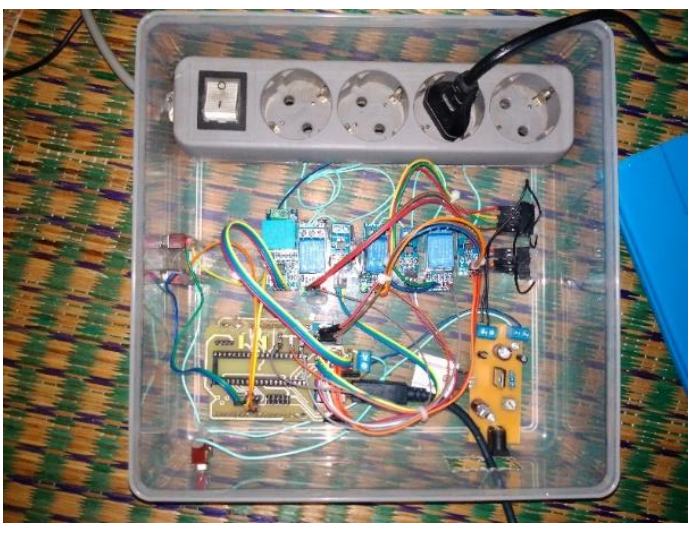

Gambar 7. Tampilan Keseluruhan Alat Tampak Atas

\section{IV.4 Pengujian Regulator LM338}

Pengujian regulator LM338 dilakukan untuk mengetahui keluaran yang dihasilkan tidak berubah dengan masukkan yang berbeda-beda.

Tabel IV.1. Pengukuran Output Regulator LM338

\begin{tabular}{cccc}
\hline \hline No & $\begin{array}{l}\text { Tegangan } \\
\text { Masukkan }\end{array}$ & $\begin{array}{l}\text { Tegangan } \\
\text { Keluaran } \\
\text { tanpa beban }\end{array}$ & $\begin{array}{l}\text { Tegangan } \\
\text { Keluaran } \\
\text { dengan beban } \\
(\mathbf{1 ~ k \Omega})\end{array}$ \\
\hline \hline 1 & $6 \mathrm{Vdc}$ & $5.09 \mathrm{Vdc}$ & $4.98 \mathrm{Vdc}$ \\
2 & $7 \mathrm{Vdc}$ & $5.09 \mathrm{Vdc}$ & $4.98 \mathrm{Vdc}$ \\
3 & $8 \mathrm{Vdc}$ & $5.09 \mathrm{Vdc}$ & $4.98 \mathrm{Vdc}$ \\
4 & $9 \mathrm{Vdc}$ & $5.09 \mathrm{Vdc}$ & $4.98 \mathrm{Vdc}$ \\
5 & $10 \mathrm{Vdc}$ & $5.09 \mathrm{Vdc}$ & $4.98 \mathrm{Vdc}$ \\
6 & $11 \mathrm{Vdc}$ & $5.09 \mathrm{Vdc}$ & $4.98 \mathrm{Vdc}$ \\
7 & $12 \mathrm{Vdc}$ & $5.09 \mathrm{Vdc}$ & $4.98 \mathrm{Vdc}$ \\
\hline \hline
\end{tabular}

Berdasarkan Tabel IV.1 dapat dijelaskan bahwa tegangan keluaran dari regulator yang dirancang berada dalam kondisi baik. Hal ini ditandai dengan tetapnya output keluaran dari regulator tersebut walaupun tegangan masukkan dinaikkan sampai $12 \mathrm{Vdc}$.

\section{IV.5 Pengujian Sensor Arus ACS712}

Pengujian sensor Arus dilakukan untuk mengetahui pengaruh sensor terhadap perubahan nilai arus. Pada pengujian ini digunakan beberapa beban dengan daya berbeda untuk mengecek nilai sensor. Persentase error dihitung dengan rumus sebagai berikut.

Error $=\frac{\text { nilai sebenarnya }- \text { nilai ukur }}{\text { nilai sebenarnya }} \times 100 \%$

\begin{tabular}{|c|c|c|c|c|}
\hline No & Beban & $\begin{array}{l}\text { Nilai } \\
\text { Sensor } \\
\text { (A) }\end{array}$ & $\begin{array}{l}\text { Nilai Arus } \\
\text { Ampere meter } \\
\text { (A) }\end{array}$ & $\begin{array}{l}\text { Error } \\
(\%)\end{array}$ \\
\hline 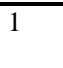 & $\begin{array}{l}\text { Kipas } \\
\text { angin }\end{array}$ & 0.08 & 0.06 & $\begin{array}{l}-33 \\
\end{array}$ \\
\hline 2 & $\begin{array}{l}\text { Penanak } \\
\text { nasi }\end{array}$ & 0.13 & 0.1 & -30 \\
\hline 3 & Laptop & 0.32 & 0.37 & 13.51 \\
\hline 4 & Dispenser & 0.85 & 0.94 & 9.57 \\
\hline
\end{tabular}

Berdasarkan Tabel 2. dapat dijelaskan bahwa rentang kesalahan nilai sensor rata-rata sebesar $10 \%$. Dengan nilai yang tidak linier untuk tiap kenaikan arus. Untuk lebih jelasnya dibuat grafik seperti pada Gambar 2.

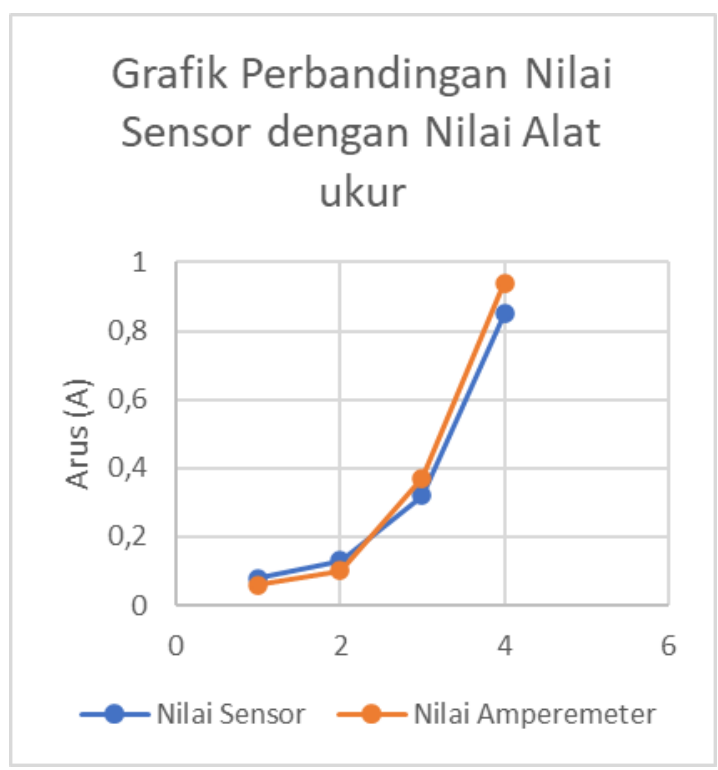

Gambar 8. Grafik Perbandingan Nilai Sensor dengan Nilai Alat Ukur

\section{IV.6 Pengujian Alat Secara Keseluruhan}

Pengujian Alat secara keseluruhan meliputi perubahan pada indikator pada komputer dengan aktual pada alat, pengaturan apakah ketika terjadi beban lebih alat bekerja secara normal, dan pengaturan kontrol alat oleh komputer. 
Tabel IV.3 Pengujian kerja alat

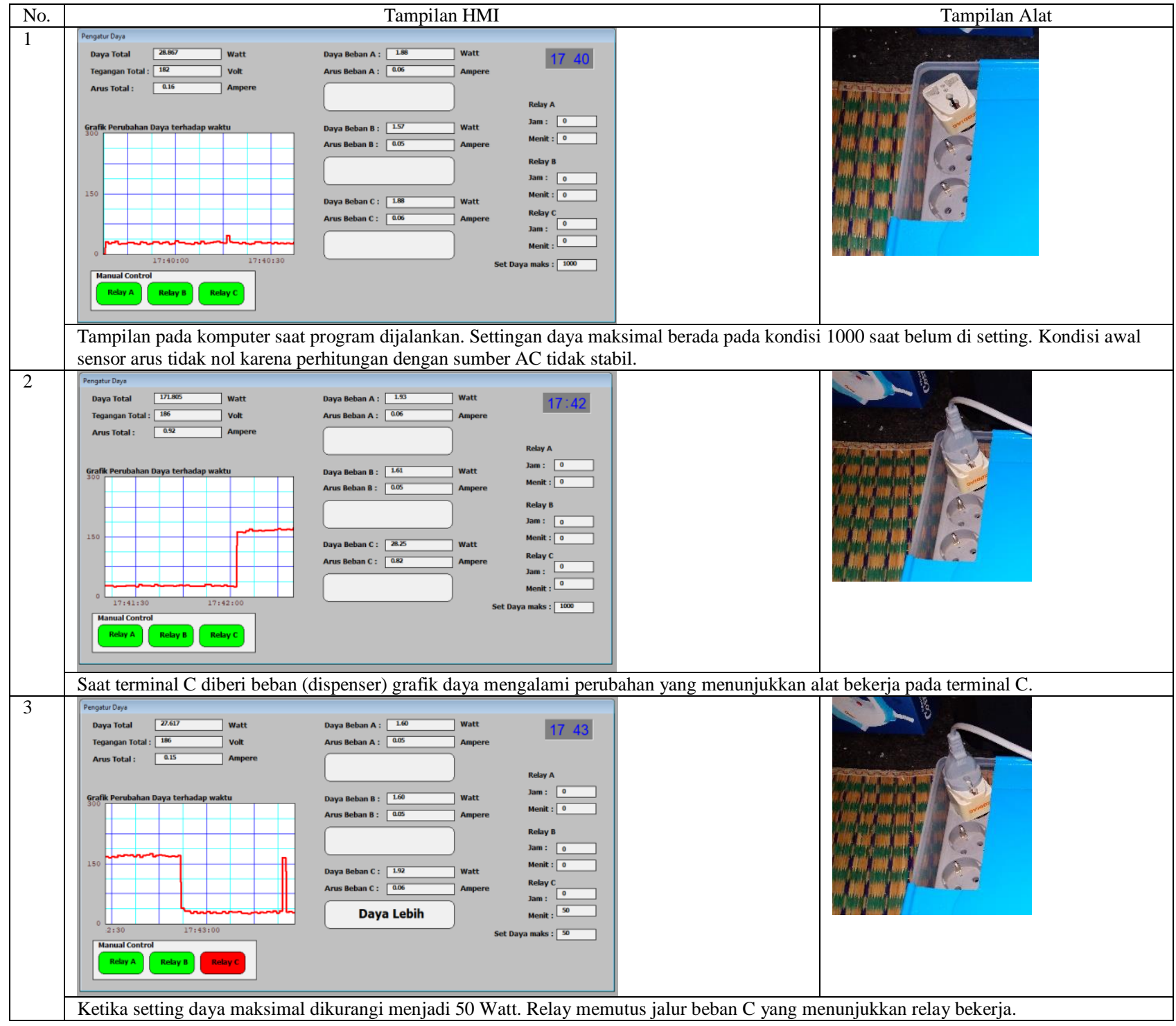


(2) UTama

E-ISSN : 2407 - 3911

P-ISSN : 2686 - 0333

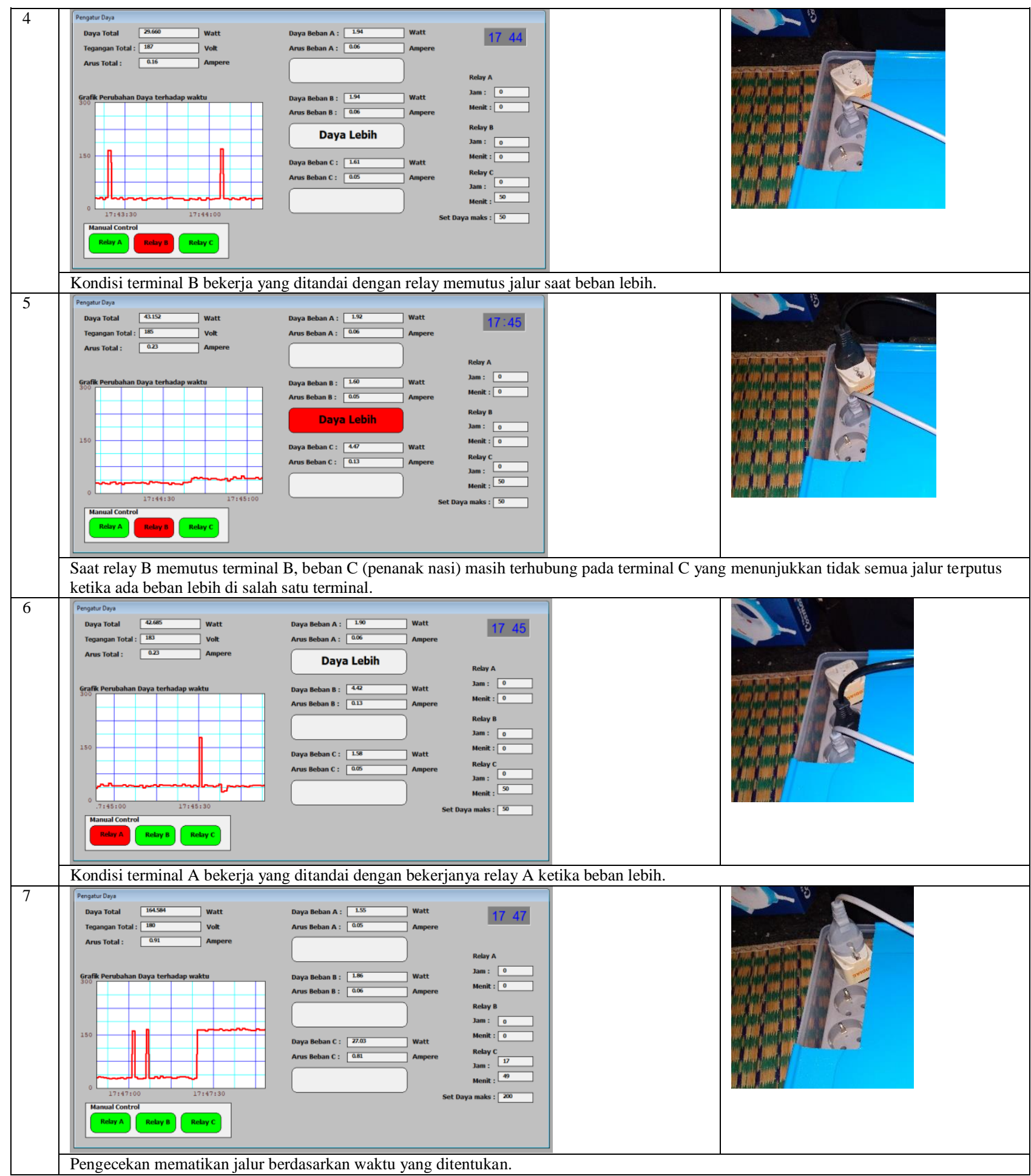

Resa Pramudita, Neris Peri Ardiansyah

Volume 7, No 2, 15 April 2021 


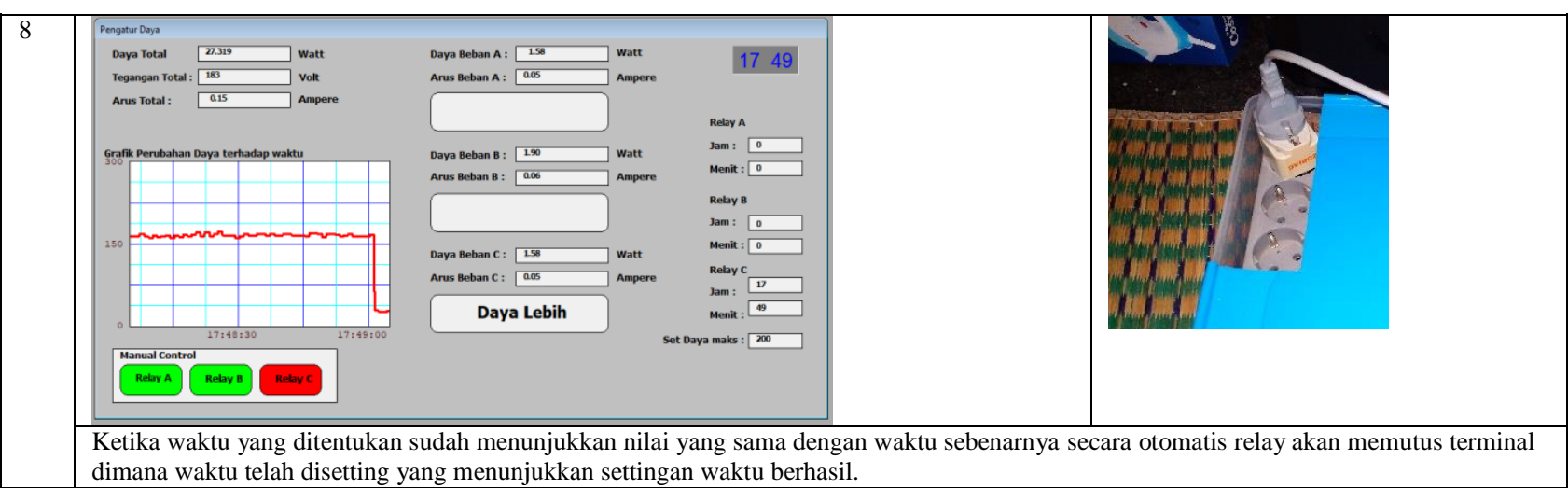

\section{KESIMPULAN DAN SARAN}

\section{V.1 Kesimpulan}

Setelah dilakukan perancangan dan pengujian maka didapatkan beberapa kesimpulan sebagai berikut.

1. Pengukuran daya listrik menggunakan sensor tegangan ZMPT101B dan sensor arus ACS712 yang terdiri dari satu buah sensor tegangan ZMPT101b dan tiga buah sensor arus ACS712, Arduino uno sebegai OPC ke komputer, modul relay, saklar, dan regulator.

2. Persentasi kesalahan sensor arus ACS712 yaitu sekitar $10 \%$ untuk tipe 20A.

\section{V.2 Saran}

Ketika akan dilakukan pengembangan alat yang lebih lanjut maka terdapat beberapa saran sebagai berikut.

1. Mencari jenis sensor yang hasilnya lebih akurat dan mudah dikendalikan.

2. Mengembangkan program sehinga alat dapat bekerja secara otomatis tanpa bantuan manusia.

3. Menambahkan pengontrol tanpa kabel melalui smartphone.

\section{REFERENSI}

Anwar, M. K. (2016). Pengertian Resistor dan Jenis nya. Retrieved from http://www.dewacupu.web.id/2016/02/pengertia n-resistor-dan-jenis-nya.html
Ardiansyah, N. P., \& Khayam, U. (2019a). Characteristics of Surface Discharge around the edges of a circle the PCB on model Plane-plane electrodes in Oil insulation. In 2019 2nd International Conference on High Voltage Engineering and Power Systems (ICHVEPS) (pp. 1-6). Denpasar: IEEE. https://doi.org/10.1109/ICHVEPS47643.2019.9 011146

Ardiansyah, N. P., \& Khayam, U. (2019b). Discharge Characteristics of Acrylic Surface Around the Needle Tip of Needle-Plane Electrodes. 2018 Electrical Power, Electronics, Communications, Controls and Informatics Seminar, EECCIS 2018 , (50), 79-84. https://doi.org/10.1109/EECCIS.2018.8692812

Ardiansyah, N. P., \& Khayam, U. (2019c). Surface Discharge Characteristics on the PCB Surface around the Edge of circle Plane-plane Electrode in Air Insulation. In 2019 International Conference on Electrical Engineering and Informatics (ICEEI) (pp. 216-221). Bandung, Indonesia:

IEEE. https://doi.org/10.1109/ICEEI47359.2019.8988 835

Ardiansyah, N. P., Khayam, U., \& Nurdiansyah, R. (2020). Measurement of Partial Discharge on PCB using RC Detector, HFCT, and Loop Antenna. Proceeding - lst FORTEIInternational Conference on Electrical Engineering, FORTEI-ICEE 2020, 64-68. https://doi.org/10.1109/FORTEIICEE50915.2020.9249908

Ardiansyah, N. P., \& Pramudita, R. (2020). Karakteristik Surface Partial Discharge di 
Sekitar Antarmuka PCB pada Pelat-Pelat Elekroda pada Isolasi Udara dan Minyak. Jurnal Ilmiah Teknologi Informasi Terapan, 6(2), 65-73.

Pramudita, R., \& Suryana, A. (2020). Rancang Bangun Trainer Terintegrasi Rangkaian Penyearah Gelombang Dan Penguat Op-Amp Berbasis Mikrokontroler Atmega 32. Jurnal Ilmiah Teknologi Infomasi Terapan, 6(1), 3641.

https://doi.org/10.33197/jitter.vol6.iss1.2019.32 7

Instruments, T. (2013). LM138/LM338 5-Amp Adjustable Regulators. Dallas: Texas Instruments.

Julien Bayle. (2013). C Programming for Arduino. Birmingham: Packt Publishing. Retrieved from http://books.google.com.my/books?id=AfNV215sPAC\&lpg=PA1\&pg=PA20\#v=onepa ge\&q \&f=false

Kadir, A. (2013). Panduan Praktis Mempelajari Aplikasi Mikrokontroler dan Pemrogramannya Menggunakan Arduino. Yogyakarta: Andi Offset.

Malik Ibnu, M., \& Juwana Unggul, M. (2009). Malik Ibnu, M \& Juwana Unggul, M., 2009, Aneka Proyek Mikrokontroler PIC16F84, Jakarta: PT Elex Media Konmputindo. Jakarta: Elex Media Konmputindo.

Zuhal. (1995). Dasar Teknik Tenaga dan Elektronika Daya. Jakarta: Gramedia. 